\title{
Early inflammatory changes in radiation-induced oral mucositis
}

\author{
Effect of pentoxifylline in a mouse model
}

Sylvia Gruber $^{1}\left[\right.$ [ Eva Bozsaky $^{1}$ Eva Roitinger ${ }^{1} \cdot$ Karoline Schwarz $^{1} \cdot$ Margret Schmidt $^{2,3} \cdot$ Wolfgang Dörr $^{1,2,3}$

Received: 19 October 2016 / Accepted: 7 February 2017 / Published online: 3 March 2017

(C) The Author(s) 2017. This article is available at SpringerLink with Open Access.

\begin{abstract}
Purpose Early inflammation is a major factor of mucosal reactions to radiotherapy. Pentoxifylline administration resulted in a significant amelioration of radiation-induced oral mucositis in the mouse tongue model. The underlying mechanisms may be related to the immunomodulatory properties of the drug. The present study hence focuses on the manifestation of early inflammatory changes in mouse tongue during daily fractionated irradiation and their potential modulation by pentoxifylline.

Materials and methods Daily fractionated irradiation with 5 fractions of $3 \mathrm{~Gy} /$ week (days $0-4,7-11$ ) was given to the snouts of mice. Groups of 3 animals per day were euthanized every second day between day 0 and 14 . Pentoxifylline $(15 \mathrm{mg} / \mathrm{kg}$, s. c.) was administered daily from day 5 to the day before sacrifice. The expression of the inflammatory proteins $\mathrm{TNF} \alpha, \mathrm{NF}-\mathrm{\kappa B}$, and IL- $1 \beta$ were analysed.
\end{abstract}

Sylvia Gruber

sylvia.gruber@meduniwien.ac.at

1 Applied and Translational Radiobiology, Dept. Radiation Oncology/CD Lab. Med. Radiation Research for Radiation Oncology, Medical University/AKH Vienna, Waehringer Guertel 18-20, 1090 Vienna, Austria

2 Dept. Radiation Oncology, Faculty of Medicine and University Hospital Carl Gustav Carus, Technische Universität Dresden, Fetscherstr. 74, 01307 Dresden, Germany

3 OncoRay - National Center for Radiation Research in Oncology, Faculty of Medicine and University Hospital Carl Gustav Carus, Technische Universität Dresden, Helmholtz-Zentrum Dresden - Rossendorf, Fetscherstr. 74, 01307 Dresden, Germany
Results Fractionated irradiation increased the expression of all inflammatory markers. Pentoxifylline significantly reduced the expression of TNF $\alpha$ and IL- $1 \beta$, but not NF- $\kappa B$. Conclusion Early inflammation, as indicated by the expression of the inflammatory markers $\mathrm{TNF} \alpha, \mathrm{NF}-\kappa \mathrm{B}$, and $\mathrm{IL}-1 \beta$, is an essential component of early radiogenic oral mucositis. Pentoxifylline differentially modulated the expression of different inflammatory markers. The mucoprotective effect of pentoxifylline does not appear to be based on modulation of NF- $\mathrm{KB}$-associated inflammation.

Keywords Fractionated irradiation · Oral mucositis $\cdot$ Head and neck cancer $\cdot$ Radiation protection $\cdot$ Animal model

Frühe entzündliche Veränderungen bei strahleninduzierter oraler Mukositis Wirkung von Pentoxifyllin im Mausmodell

\section{Zusammenfassung}

Hintergrund und Ziel Frühe entzündliche Veränderungen sind ein bedeutender Faktor während der Strahlenreaktion der Schleimhaut. Die Behandlung mit Pentoxifyllin erzielte eine signifikante Minderung strahleninduzierter oraler $\mathrm{Mu}$ kositis im Mauszungenmodel. Die zugrundeliegenden Mechanismen sind potenziell auf die immunomodulatorischen Eigenschaften des Wirkstoffs zurückzuführen. Die vorliegenden Untersuchungen fokussieren daher auf die Manifestation früher entzündlicher Veränderungen in der Mauszunge während täglich fraktionierter Bestrahlung und deren potenzieller Modifikation durch Pentoxifyllin.

Material und Methoden Täglich fraktionierte Bestrahlung mit 5 Fraktionen zu 3 Gy/Woche (Tage 0-4 und 7-11) wurde auf die Schnauzen der Mäuse appliziert. Gruppen von je 3 Tieren wurden in 2-tägigem Abstand eingeschläfert. 
Pentoxifyllin $(15 \mathrm{mg} / \mathrm{kg}$, s. c.) wurde täglich von Tag 5 bis zum Tag vor der Euthanasie verabreicht. Die Expression der Entzündungsproteine TNF $\alpha, N F-\kappa B$ und IL- $1 \beta$ wurde analysiert.

Ergebnisse Die fraktionierte Bestrahlung erhöhte die Expression aller entzündlicher Marker. Pentoxifyllin reduzierte die Expression von TNF $\alpha$ und IL-1 $\beta$ signifikant, nicht jedoch die Expression von NF-кB.

Schlussfolgerung Frühe Entzündung, gekennzeichnet durch die Expression der entzündlichen Marker TNF $\alpha$, NF-אB und IL-1 $\beta$, ist eine essenzielle Komponente der frühen radiogenen oralen Mukositis. Pentoxifyllin modulierte die Expression jener Marker auf unterschiedliche Weise. Der mukoprotektive Effekt von Pentoxifyllin scheint nicht auf NF-кB-assoziierter antientzündlicher Wirkung zu beruhen.

Schlüsselwörter Fraktionierte Bestrahlung - Orale Mukositis · Kopf-und-Hals-Tumore · Strahlenschutz · Tiermodell

\section{Introduction}

Oral mucositis is the most important early radiotherapy-related adverse event in head-and-neck cancer patients [1,2]. Severe confluent epithelial radiation reactions, experienced by the majority of patients, significantly impact the patients' quality of life with pain, swallowing, and speaking difficulties [3]. Mucositis-related hospitalization and treatment interruptions [4] compromise the therapeutic outcome [5]. Current prophylactic and interventional strategies are purely symptomatic [6]. Oral mucositis is associated with a pronounced early inflammatory response. This offers a target for biology-based mucositis-preventing strategies [7, 8].

Pentoxifylline (PTX), a nonspecific phosphodiesterase inhibitor, may improve tumor oxygenation due to rheologic effects, but may also ameliorate treatment-associated normal tissue morbidity through modulation of inflammatory changes [9]. When tested in a preclinical model of radiation-induced early oral mucositis, PTX was found to significantly reduce the incidence of mucosal ulceration in daily fractionation studies in the established mouse tongue model. PTX treatment yielded the most pronounced radioprotective effect, when the administration interval included the second treatment week of fractionation. This is the time when repopulation, the adaptive epithelial radiation response [10], is already fully active. Time course parameters of oral mucositis, i. e., latent time to the onset of mucosal ulcerations and their respective duration, however, were found virtually unchanged. [11].

The present study was then initiated in the same experimental model in order to characterize inflammation-related biological mechanisms of action of PTX. For this, the ex- pression of the key inflammatory mediators interleukin-1 (IL-1-) $\beta$, tumor necrosis factor (TNF) $\alpha$, and nuclear factor kappa-light-chain-enhancer of activated B cells (NF- $\mathrm{KB}$ ) during daily fractionated irradiation and the effect of additional PTX treatment was quantified in immunohistochemical investigations. Inflammatory changes are frequently observed during the development of oral mucositis and, hence, present an option to develop a biology-oriented treatment strategy. NF- $\kappa B$ is hypothesized to be one of the key signaling molecules in this aspect $[8,12]$ and was found upregulated in biopsies of oral mucosa of patients undergoing myoablative therapy [8]. NF- $\kappa \mathrm{B}$ is an evolutionary-conserved signaling molecule that, as an inducible transcription factor, regulates reactions to changes in the environment. Although involved in the transcriptional control of various genes, its main function is the regulation of the immune system. NF- $\mathrm{KB}$ is activated upon numerous stimuli, following either a classical, an alternative, or an atypical pathway. Differences in the activation pathways arise from different subsets of stimulatory molecules and, furthermore, from subsequently recruited and differently processed intracellular binding partners. However, all pathways lead to NF- $\mathrm{KB}$ activation via inducible degradation of the inhibitory protein complex that sequesters NF- $\kappa \mathrm{B}$ in the cytoplasm, followed by NF- $\kappa B$ nuclear translocation and gene transcription [13]. It activates proinflammatory cytokines, chemokines, growth and survival factors [14]. This includes TNFa, which in turn impacts on NF- $\kappa \mathrm{B}$ expression in a positive feedback loop and presents the model stimulus for the classical NF$\kappa \mathrm{B}$ activation pathway. TNF $\alpha$ mainly regulates antiapoptotic genes and, aberrantly expressed, is involved in several pathologic conditions, e. g., rheumatoid arthritis [15]. IL- $1 \beta$ presents another NF- $\kappa$ B-activated protein, which can potentiate its own synthesis in autoregulatory pathways and activates NF- $\kappa B$ in return $[16,17]$. IL- $1 \beta$ is produced by activated macrophages and is involved in various cellular processes. Most importantly, it is a key mediator of the inflammatory response [18].

\section{Material and methods}

\section{Animals and housing}

In the present experiments, mice of the inbred $\mathrm{C} 3 \mathrm{H} / \mathrm{Neu}$ strain from the breeding facility of Medical Faculty Carl Gustav Carus, Dresden, Germany were housed under specified pathogen-free conditions with controlled temperature $\left(21-24{ }^{\circ} \mathrm{C}\right)$ and humidity $(30-50 \%)$. An automated light program provided a 12/12-h light/dark rhythm, with lights on from 06:00 am to 06:00 pm. Maximum ten animals were kept in size 3 Macrolon ${ }^{\circledR}$ cages on saw dust bedding (Sniff $3 / 4$, Altrogge, Lage, Germany) with free access to standard 
mouse diet (Altromin 1326, Altrogge, Lage, Germany) and filtered city tap water from standard perspex drinking bottles.

\section{Irradiation technique}

The technique for irradiation of oral mucosa was described in detail elsewhere $[11,19]$. In brief, percutaneous irradiation of the entire snouts of the animals was performed with an YXLON MG325 device (Yxlon International X-ray $\mathrm{GmbH}$, Hamburg, Germany), operated at $200 \mathrm{kV}$ with a tube current of $20 \mathrm{~mA}$. The animals were guided into plastic tubes (inner diameter $28 \mathrm{~mm}$ ). Conical holes in a perspex block at the front end of the tubes served for standardized positioning of the snouts. The back ends of the tubes were closed to prevent withdrawal of the animals. Eight animals were irradiated simultaneously. The bodies of the mice were shielded with $6 \mathrm{~mm}$ of lead equivalent MCP-96 (HEK Medizintechnik, Lübeck, Germany); the treatment field encompassed the snouts including the entire tongue. The dose homogeneity between the individual snout irradiation fields was $\pm 3 \%$.

\section{Experimental design}

Daily fractionated irradiation with 5 fractions of 3 Gy/week was applied over 2 weeks (days 0-4, 7-11). The study comprised three experimental arms: irradiation alone (IR), irradiation in combination with PTX administration (IR+PTX), and PTX treatment alone (PTX). PTX was administered subcutaneously at a dose of $15 \mathrm{mg} / \mathrm{kg}$ from day 5 until the day before sacrifice; on irradiation days, the drug was given $1 \mathrm{~h}$ before irradiation in the IR+PTX arm. In both arms, groups of animals ( $n=3)$ were sacrificed every second day, and their tongues excised at the base for further investigations. Three untreated and unirradiated mice served as a control group.

\section{Histological preparation}

The tongues were incubated in $4 \%$ paraformaldehyde for 24-48 h, cut along the median line, and subjected to routine paraffin embedding. Sections of $3 \mu \mathrm{m}$ were mounted on Superfrost ${ }^{\circledR}$ plus charged glass slides (Gerhard Menzel $\mathrm{GmbH}$, Braunschweig, Germany) and dried at $37{ }^{\circ} \mathrm{C}$ overnight. Subsequently, the sections were deparaffinized and rehydrated through xylene and a graded alcohol series. Heat-mediated antigen retrieval for IL- $1 \beta$ and NF- $\kappa B$ was performed with citrate buffer, $\mathrm{pH} 6.0$, boiling in a microwave set to full power for $20 \mathrm{~min}$. For TNF $\alpha$, epitope unmasking was performed with EDTA buffer, $\mathrm{pH}$ 9.0, for $10 \mathrm{~min}$, also boiling in a microwave set to full power. Endogenous peroxidase activity was blocked (3\% hydrogen peroxide, $10 \mathrm{~min})$. The sections were then incubated with normal goat serum $(1: 200)$, using a Vectastain ${ }^{\circledR}$ ABC Kit (Vectastain ABC Kit, Vector Laboratories, Burlingame, CA, USA), for $1 \mathrm{~h}$ at room temperature, followed by overnight incubation at $4{ }^{\circ} \mathrm{C}$ with the primary antibodies. Anti-TNF $\alpha$ (Abcam, Cambridge, MA, USA; Cat. no. 6671; rabbit polyclonal) was used at a concentration of $1: 700$, anti-IL-1 $\beta$ (Novus Biologicals, Littleton, CO, USA; Cat. no. NBP119775; rabbit polyclonal) at a concentration of 1:400 and anti-NF-кB p50 (Abcam, Cambridge, MA, USA; Cat. no. 7971; rabbit polyclonal) at a concentration of $1: 100$. These concentrations had been defined in previous protocol optimization studies. A second section on the same slide was incubated with the same concentration of rabbit IgG (Dianova GmbH, Hamburg, Germany; Cat. no. 011-000-003) and served as a negative control. The secondary antibody was added for $1 \mathrm{~h}$ at room temperature. Subsequently, the sections were incubated with the avidin-biotin complex solution for $1 \mathrm{~h}$ at room temperature. The enzyme reaction was visualized by 3,3-diaminobenzidine (DAB) substrate (Vectastain ABC Kit, Vector Laboratories, Burlingame, CA, USA). Nuclear counterstaining was performed with hematoxylin $(5 \mathrm{~min})$. Then, the slides were dehydrated in a graded alcohol series, cleared in xylene and coverslipped.

\section{Histological analysis}

Analysis was performed with an Olympus light microscope at $400 \times$ magnification. Cytoplasmic TNF $\alpha$ expression could not be attributed to individual cells, hence, not the fraction of expressing, positive cells, but the general staining intensity was determined, separately for the germinal (proliferative) and the functional (postmitotic) nucleated layers of the epithelium. The signal intensity, corresponding to the amount of secreted protein, was assessed semiquantitatively with an arbitrary score from 0 (no signal), 1 (weak signal), 2 (intermediate signal) to 3 (strong signal). The fraction of $\mathrm{NF}-\kappa \mathrm{B}$ p50 positive cell nuclei was evaluated separately for the germinal and the functional epithelium. In addition, the respective staining intensity was scored as described above for TNF $\alpha$. IL-1 $\beta$ was not found in the epithelium, but exclusively expressed in macrophages in underlying tongue tissues. IL-1 $\beta$ positive macrophages were counted within at least 15 visual microscopic fields. The number of IL-1 $\beta$ expressing macrophages in unirradiated and untreated control tongue sections was set to $100 \%$, all further day- and experimental arm specific mean values refer to this normalization. The respective staining intensity was determined (see above). 


\section{Statistical analysis}

For statistical analysis, the SPSS statistical software (SPSS Inc., Chicago, IL, USA) was used. Mean values and standard deviation (SD) were calculated for each animal, which then served to calculate the mean and standard error for each experimental group. The analysis of variance (oneway ANOVA) was used to test for the significance of a difference between the mean values. A $p$-value of $<0.05$ was regarded statistically significant.

\section{Results}

Representative histophotographs of immunohistochemical staining for TNF $\alpha$, NF- $\kappa B$ p50, and IL- $1 \beta$ in control specimen and on days 6 and 14 are presented in Fig. 1.

\section{TNF $\alpha$}

TNF $\alpha$ expression was minor in unirradiated and untreated control samples, with an average staining intensity of
0.6 a.u. in the germinal layer and of 0.8 a.u. in the functional compartment, respectively. With the onset of daily fractionated irradiation, as illustrated in Fig. 2, TNF $\alpha$ expression increased progressively. The expression maximum was observed on day 12 (2.5 a.u.).

In the germinal epithelial layers, additional PTX treatment reduced TNF $\alpha$ on day 0 ( 0.2 a.u.) and day 2 ( 0.2 a.u. $)$ relative to only irradiated specimen ( 0.6 a.u. and 0.8 a.u.), respectively. Subsequently, the germinal expression in the PTX-treated experimental arm progressed similarly to only irradiated specimen until day 10, although the TNFa expression remained substantially lower compared to irradiation alone. The expression maximum on day 12 was reduced to 1.5 a.u. and on day 14 , expression levels were found to be significantly below those for irradiation alone $(p=0.037)$ and within the normal range (0.75 a.u.) (Fig. 2a). In the functional epithelial compartment daily fractionated irradiation induced a progressive increase in $\mathrm{TNF} \alpha$ expression with a maximum on day 12 (2.1 a.u.). With additional PTX treatment, TNF $\alpha$ expression developed similar to that after irradiation alone, but was constantly substantially lower, however, with a significant difference only being obtained
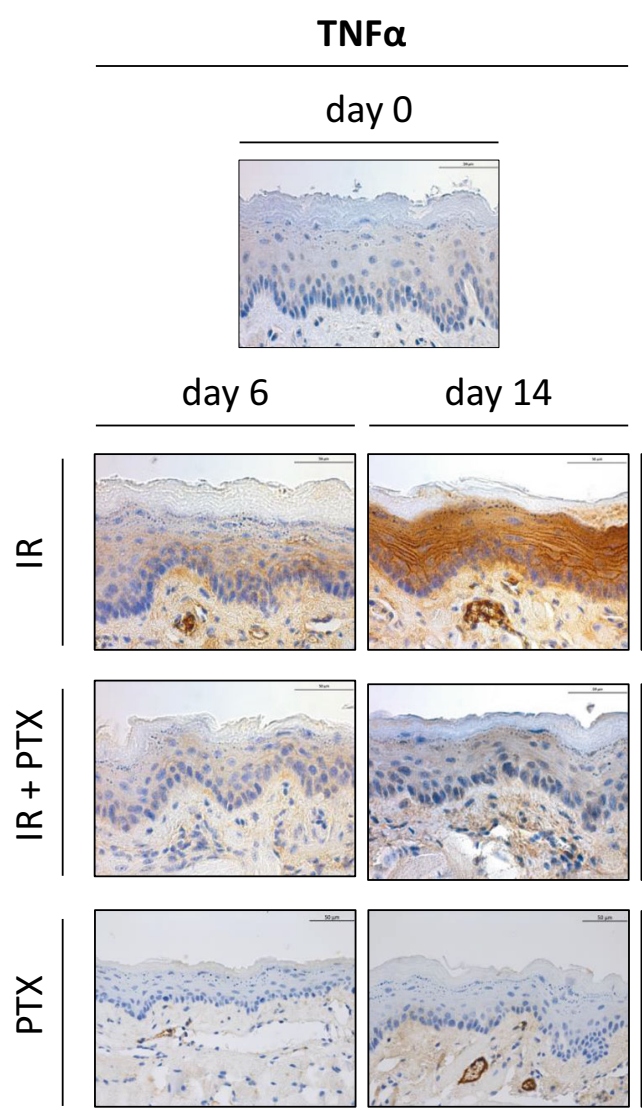
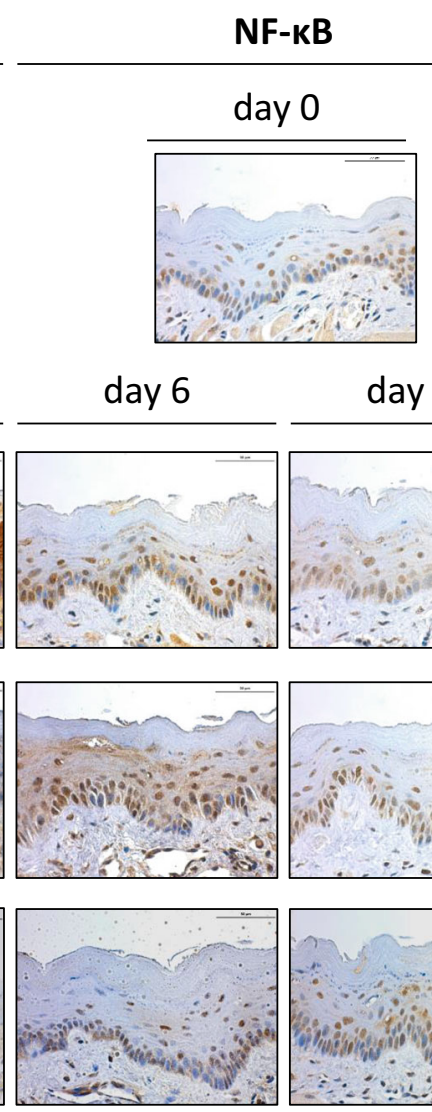
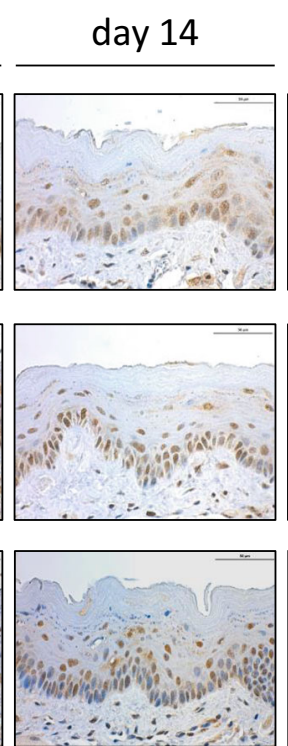

IL1 $\beta$
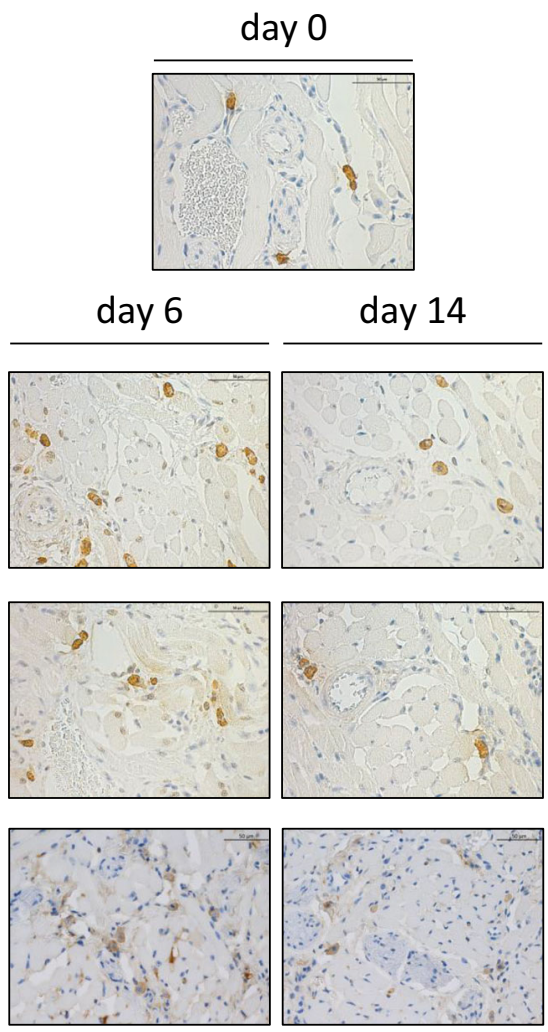

Fig. 1 TNF $\alpha, N F-\kappa B$ p50, and IL-1 $\beta$ expression during fractionated irradiation \pm PTX and PTX alone. Representative histophotographs of lower mouse tongue stained for TNF $\alpha, \mathrm{NF}-\mathrm{\kappa B}$ p50 (epithelial staining), and IL-1 $\beta$-positive macrophages (deeper tongue tissue, in close proximity to blood vessels). Figures represent day 0 (unirradiated and untreated controls), day 6 and day 14 during fractionated irradiation alone (IR), with additional PTX administration $(I R+P T X)$, and PTX treatment alone $(P T X)$. PTX treatment reduced the radiation-induced expression increase of

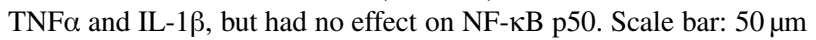



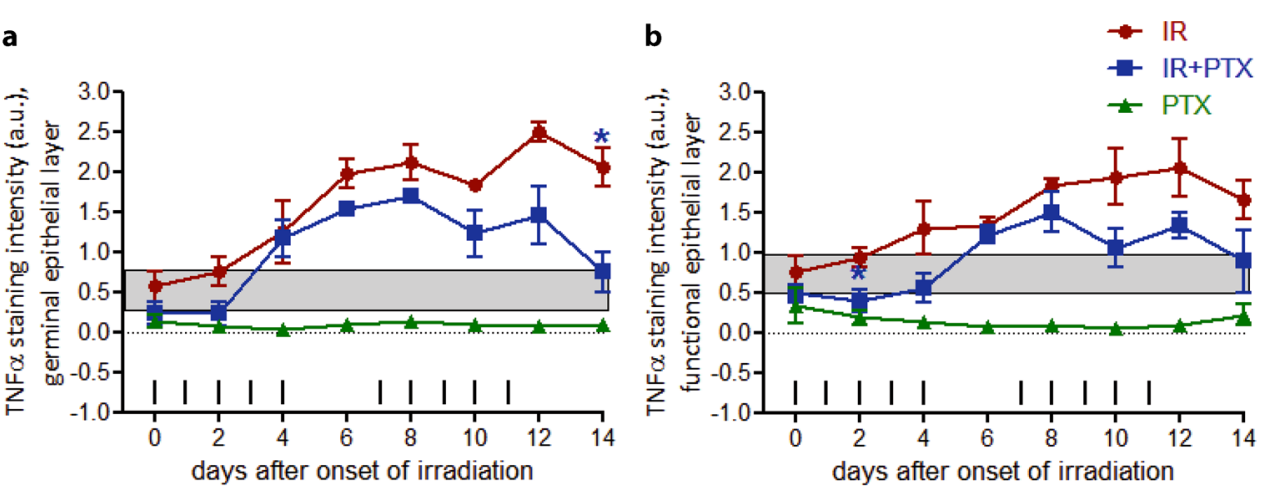

Fig. 2 Effect of fractionated irradiation \pm PTX and PTX alone on TNF $\alpha$ expression. TNF $\alpha$ expression was analyzed in the epithelium, in the germinal (a) and functional (b) compartments, respectively. The staining signal intensity was scored semiquantitatively with an arbitrary score of 0 (no signal), 1 (weak), 2 (intermediate), or a maximum of 3 (strong). Data points represent the mean of 3 animals, error bars indicate \pm 1 standard deviation $(S D)$. The shaded areas illustrate the mean $( \pm 1 \mathrm{SD})$ from 3 control animals. The fractionation protocol is indicated on top of the abscissae. $P T X$ pentoxifylline, $I R$ irradiation. $* p<0.05$

Fig. 3 Effect of fractionated irradiation \pm PTX and PTX alone on NF- $\kappa \mathrm{B}$ p50 expression. $\mathrm{NF}-\kappa \mathrm{B}$ p50 expression was analyzed in the epithelium, in the germinal (a) and functional (c) compartments, respectively. The staining signal intensity was scored semiquantitatively with an arbitrary score of 0 (no signal), 1 (weak), 2 (intermediate), or a maximum of 3 (strong) in both compartments as well (b and d). Data points represent the mean of 3 animals, error bars indicate \pm 1 standard deviation $(S D)$. The shaded areas illustrate the mean $( \pm 1 \mathrm{SD})$ from 3 control animals. The fractionation protocol is indicated on top of the abscissae. PTX pentoxifylline, $I R$ irradiation
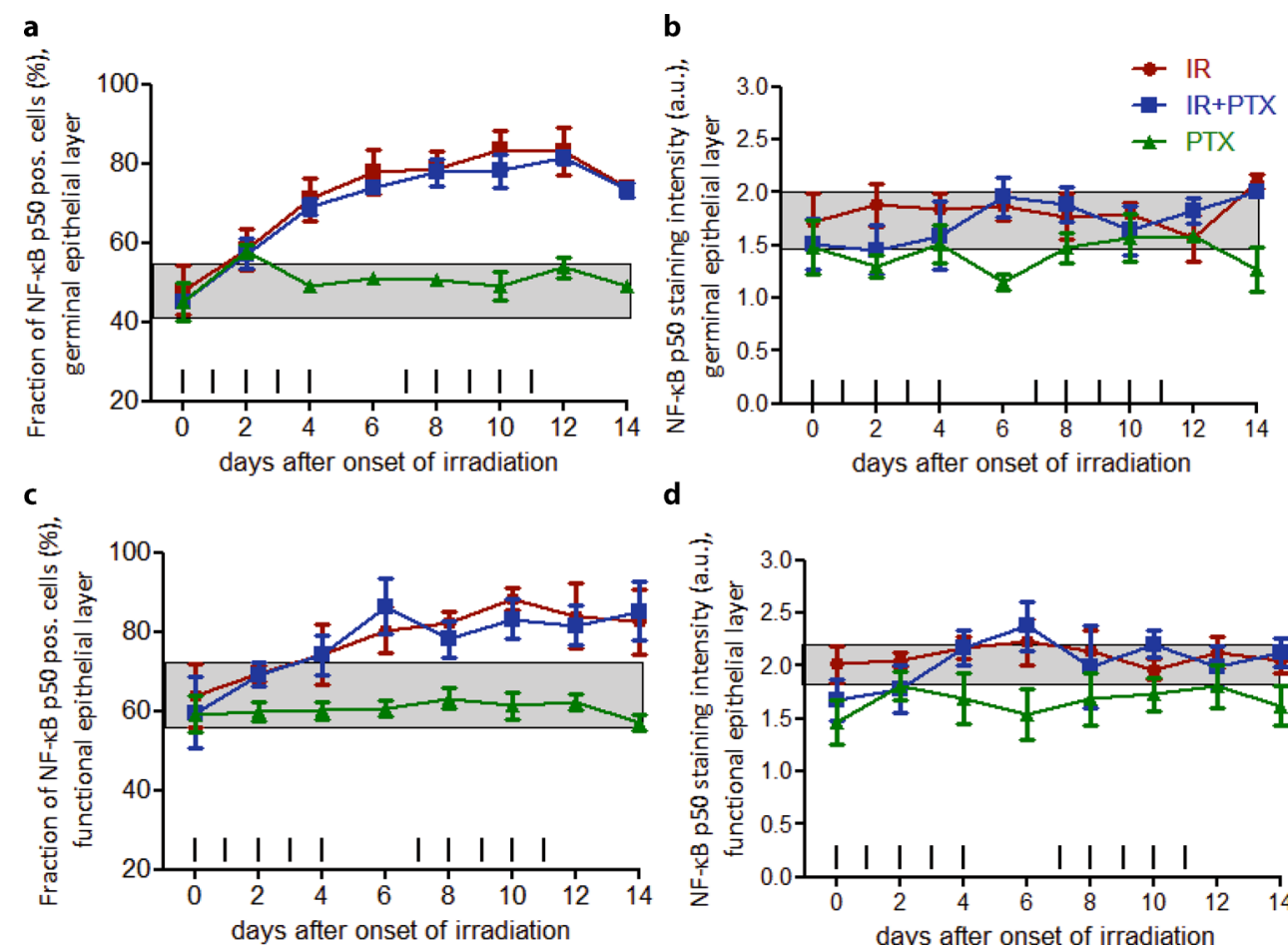

d



at day 2 ( $p=0.022$ ) (Fig. 2b). PTX treatment alone reduced TNF $\alpha$ levels to subnormal values in both the germinal and the functional epithelial layers. Reduced epithelial TNF $\alpha$ expression remained throughout the PTX treatment time (Fig. 2a,b).

\section{NF-אB p50}

In control specimen, $47.9 \%$ of cell nuclei in the germinal epithelial compartment were NF-кB p50 positive. With daily fractionated irradiation, NF- $\kappa \mathrm{B}$ p50 expression increased over the normal range on day $2(58.3 \%)$ and progressively expanded to a maximum of $83 \%$ on day 12 . NF- $\kappa \mathrm{B}$ p50 staining intensity in the individual, positive cell nuclei was not affected by daily fractionated irradiation throughout the study period. Both the fraction of NF- $\mathrm{BB}$ p50 positive cell nuclei and their respective staining intensity remained unchanged by PTX treatment (Fig. 3a,b).

In the postmitotic, functional epithelial compartment, $67.2 \%$ of cell nuclei expressed NF-kB p50 in control sections. Daily fractionated irradiation progressively increased the NF- $\mathrm{kB}$ p50 expression to a maximum of $88.3 \%$ nuclei on day 10 . NF- $\kappa \mathrm{B}$ p50 staining intensity remained within the control range during the study period. Additional PTX treatment had no effect on the fraction of cell nuclei pos- 



Fig. 4 Effect of fractionated irradiation \pm PTX and PTX alone on IL-1 $\beta$ expression in macrophages. IL- $1 \beta$ expression was exclusively found in macrophages (deeper tongue tissue). The number of macrophages positive for IL-1 $\beta$ (a) as well as the staining signal intensity (b) was evaluated. The staining intensity was scored semiquantitatively with an arbitrary score of 0 (no signal), 1 (weak), 2 (intermediate), or a maximum of 3 (strong). Data points represent the mean of 3 animals, error bars indicate \pm 1 standard deviation $(S D)$. The shaded areas illustrate the mean $( \pm 1$ SD) from 3 control animals. The fractionation protocol is indicated on top of the abscissae. PTX pentoxifylline, IR irradiation. *p $p<0.05$

itively stained for NF-אB p50 or the respective staining intensity (Fig. 3c,d).

PTX treatment alone did not substantially affect the percentage of NF- $\kappa \mathrm{B}$ p50 positive cell nuclei or their respective staining intensity. A minor reduction of the staining intensity in only the functional layer was observed (Fig. 3a-d).

\section{IL-1及}

Daily fractionated irradiation progressively increased the number of IL-1 $\beta$ positive macrophages to a maximum of $190 \%$ on day 6 . Afterwards, the number of IL-1 $\beta$ positive macrophages declined despite ongoing irradiation, and normal values were restored on day 12 (Fig. 4a). IL-1 $\beta$ staining intensity did not change systematically throughout the study period. Initial values of 1.8 a.u. increased to a maximum of 2.1 a.u. on days $4-8$. Subsequently, the staining intensity reentered the normal range.

Additional PTX treatment kept the number of IL-1 $\beta$ expressing macrophages close to or within the normal range until day 8 . The IL-1 $\beta$ expression maximum was delayed to day 10 and reduced to $173 \%$, relative to controls. However, the only significant difference to only irradiated specimen was found on day $6(p=0.022)$. The subsequent restoration of normal values was complete on day 14 . IL- $1 \beta$ staining intensity remained lower, compared to only irradiated samples and within control ranges throughout the study period (Fig. 4b). PTX treatment alone had no significant effects on either the number of IL-1 $\beta$ positive macrophages or their respective staining intensity. Both parameters remained largely within the control range (Fig. 4a,b).

\section{Discussion}

Virtually all head-and-neck cancer patients experience some degree of oral mucositis during their radio(chemo)therapy, the majority develops a severe, confluent reaction $[1,20]$. Oral mucositis is associated with significant reduction of the patients quality of life, bears the risk for systemic infections, due to the loss of the epithelial barrier function, and for consequential late effects in the oral cavity [21, 22]. No biology-based treatment has so far been implemented into clinical practice.

PTX treatment during daily fractionated irradiation resulted in a significant reduction of the incidence of oral mucositis in the mouse tongue model [11] This may be attributed to a modulation of inflammatory processes which are suggested to be a major component of (early) normal tissue radiation effects [23, 24], including mucositis [25, 26]. Early inflammation is regularly observed during the clinical manifestation of oral epithelial ulceration in patients. NF- $\kappa B$ seems to play a key role in this aspect $[8,12]$. With TNF $\alpha$ and IL-1 $\beta$, stimuli for both the classical and the alternative NF- $\mathrm{KB}$ activation pathway have been investigated this study. Furthermore, both cytokines are involved in nociception [27]. PTX was found to ameliorate pain in preclinical as well as clinical studies, likely due to reduced TNF $\alpha$ and IL-1 release [28, 29]. This indicates that PTX might have an antihyperalgesic effect, reducing the significant mucositis-associated pain burden. This effect, however, is not substantiated in the animal model used in the present study.

\section{Irradiation alone}

In our mouse tongue model, daily fractionated irradiation rapidly induced the expression of all inflammatory markers 
investigated. In contrast to $\mathrm{TNF} \alpha$ and $\mathrm{NF}-\kappa \mathrm{B}$ expression levels, which remained considerably high throughout the study period, IL-1 $\beta$ was found to be downregulated at the end of the first treatment week, despite ongoing irradiation. This corresponds to the time of onset of repopulation, i. e., the regenerative response of oral epithelium to fractionated irradiation $[10,30]$. A potential interaction with the epithelial regenerative radiation response is hence highly likely.

\section{Irradiation with additional PTX administration}

PTX exhibits potent anti-inflammatory effects [31, 32], directly inhibits TNF $\alpha$, and reduces inflammation in multiple preclinical models [33-35], chemotherapy-induced intestinal (CPT-11) and oral (5-FU) mucositis [36, 37]. In combination with daily fractionated irradiation, PTX had significant effects on TNF $\alpha$ and IL- $1 \beta$, but no effect on the mutual downstream protein NF- $\kappa$ B. Being a central mediator of inflammation and other biological processes, NF$\kappa \mathrm{B}$ is regulated by multiple pathways [38]. TNF $\alpha$ and IL1 are considered major NF-אB stimuli. However, TNF $\alpha$ is only one of the ligands of the tumor necrosis factor receptor (TNFR) superfamily, which consists of 19 ligands and 30 receptors [39], all of which result in the activation of the NF- $\kappa B$ pathway. In addition to the TNFR superfamily, Tolllike receptor (TLR) signaling can also result in NF- $\kappa B$ activation. TLRs react upon stimulation by damage-associated molecular pattern molecules (DAMP) and pathogen-associated molecular pattern molecules (PAMP) [40]. Especially DAMPs are likely to be released after irradiation and also PAMP signaling is likely due to changes in the host oral microbiome [41]. Hence, it appears to be highly likely that lacking TNF $\alpha$ and/or IL-1 $\beta$ is substituted by other stimuli. Activation could also occur via the atypical activation pathway. In addition to ligand-mediated activation, NF- $\kappa \mathrm{B}$ can be stimulated by reactive oxygen species, such as hydrogen peroxide, which is abundantly produced during the radiolysis of intracellular water [42]. Further oxidants, such as singlet oxygen and superoxide and reactive nitrogen species have been shown to active NF- $\mathrm{KB}$ and are released by immune cells during inflammation [43]. This hypothesis is supported by the missing effect of specific TNF $\alpha$ inhibition with infliximab on oral mucositis, obtained in another study in the mouse tongue model [44].

The central role of NF- $\mathrm{KB}$ in the regulation of the inflammatory response promotes further targeting of this pathway as a treatment strategy to reduce radio(chemo)therapy-induced oral mucositis. Recently, a reduction of radiationinduced oral mucositis by specific targeting of NF- $\mathrm{KB}$ was demonstrated in the mouse tongue model [45].

\section{PTX alone}

In our study, PTX treatment alone left the expression levels of all inflammatory mediatory investigated largely unchanged and within control ranges. PTX most likely exerts its mucositis-ameliorating activity through a mechanism other than modulation of NF- $\mathrm{KB}$ associated inflammation.

Presumably, the recently demonstrated PTX-mediated reduction of radiation-induced early epithelial hypoxia [19] accounts for the beneficial effect. Further mechanisms, e. g., modulation of cell junctions or increased epithelial proliferation could also contribute. Modulation of epithelial proliferation by PTX is currently being investigated.

\section{Conclusion}

Based on these results, the mucositis-ameliorating effects of PTX, observed in functional studies [11], cannot be attributed to a reduction of radiation-induced NF- $\mathrm{KB}$ associated inflammatory changes. Nevertheless, reduced TNF $\alpha$ and IL- $1 \beta$ expression could alleviate mucositis-associated pain sensation. The anti-inflammatory approach remains a promising treatment strategy for the oral mucositis. Further analyses of the mechanistic effects of PTX during the development of radiation-induced oral mucositis are required to fully elucidate its potential as mucositis-ameliorating treatment strategy.

Acknowledgements The financial support by the Federal Ministry of Science, Research and Economy and the National Foundation for Research, Technology and Development is gratefully acknowledged. Open access funding provided by Medical University of Vienna.

\section{Compliance with ethical guidelines}

Conflict of interest S. Gruber, E. Bozsaky, E. Roitinger, K. Schwarz, M. Schmidt and W. Dörr declare that they have no competing interests.

Ethical standards All institutional and national guidelines for the care and use of laboratory animals were followed. All experiments were performed with approval by the respective authorities (Landesdirektion Sachsen, file no. 24D-9168.11-1/2006-14).

Open Access This article is distributed under the terms of the Creative Commons Attribution 4.0 International License (http:// creativecommons.org/licenses/by/4.0/), which permits unrestricted use, distribution, and reproduction in any medium, provided you give appropriate credit to the original author(s) and the source, provide a link to the Creative Commons license, and indicate if changes were made.

\section{References}

1. Wygoda A, Rutkowski T, Hutnik M et al (2013) Acute mucosal reactions in patients with head and neck cancer. Three patterns 
of mucositis observed during radiotherapy. Strahlenther Onkol 189(7):547-551

2. Cvek J, Kubes J, Skacelikova E et al (2012) Hyperfractionated accelerated radiotherapy with concomitant integrated boost of $70-75$ Gy in 5 weeks for advanced head and neck cancer. A phase I dose escalation study. Strahlenther Onkol 188(8):666-670

3. Elting LS, Keefe DM, Sonis ST et al (2008) Patient-reported measurements of oral mucositis in head and neck cancer patients treated with radiotherapy with or without chemotherapy: demonstration of increased frequency, severity, resistance to palliation, and impact on quality of life. Cancer 113(10):2704-2713

4. Russo G, Haddad R, Posner M et al (2008) Radiation treatment breaks and ulcerative mucositis in head and neck cancer. Oncologist 13(8):886-898

5. Bese NS, Hendry J, Jeremic B (2007) Effects of prolongation of overall treatment time due to unplanned interruptions during radiotherapy of different tumor sites and practical methods for compensation. Int J Radiat Oncol Biol Phys 68(3):654-661

6. Lalla RV, Bowen J, Barasch A et al (2014) MASCC/ISOO clinical practice guidelines for the management of mucositis secondary to cancer therapy. Cancer 120(10):1453-1461

7. Bastos Moura JF, Mota JM, Leite CA et al (2015) A novel model of megavoltage radiation-induced oral mucositis in hamsters: Role of inflammatory cytokines and nitric oxide. Int $\mathrm{J}$ Radiat Biol 91(6):500-509

8. Logan RM, Gibson RJ, Sonis ST et al (2007) Nuclear factorkappaB (NF-kappaB) and cyclooxygenase-2 (COX-2) expression in the oral mucosa following cancer chemotherapy. Oral Oncol 43(4):395-401

9. Nieder C, Zimmermann FB, Adam M et al (2005) The role of pentoxifylline as a modifier of radiation therapy. Cancer Treat Rev 31(6):448-455

10. Dorr W (1997) Three A's of repopulation during fractionated irradiation of squamous epithelia: asymmetry loss, acceleration of stem-cell divisions and abortive divisions. Int J Radiat Biol 72(6):635-643

11. Gruber S, Schmidt M, Bozsaky E et al (2015) Modulation of radiation-induced oral mucositis by pentoxifylline: preclinical studies. Strahlenther Onkol 191(3):242-247

12. Sonis ST (2002) The biologic role for nuclear factor-kappaB in disease and its potential involvement in mucosal injury associated with anti-neoplastic therapy. Crit Rev Oral Biol Med 13(5):380-389

13. Perkins ND (2006) Post-translational modifications regulating the activity and function of the nuclear factor kappa B pathway. Oncogene 25(51):6717-6730

14. Hayden MS, Ghosh S (2004) Signaling to NF-kappaB. Genes Dev 18(18):2195-2224

15. Schutze S, Wiegmann K, Machleidt T et al (1995) TNF-induced activation of NF-kappa B. Immunobiology 193(2-4):193-203

16. Hiscott J, Marois J, Garoufalis J et al (1993) Characterization of a functional NF-kappa B site in the human interleukin 1 beta promoter: evidence for a positive autoregulatory loop. Mol Cell Biol 13(10):6231-6240

17. Adams V, Nehrhoff B, Spate U et al (2002) Induction of iNOS expression in skeletal muscle by IL-1beta and NFkappaB activation: an in vitro and in vivo study. Cardiovasc Res 54(1):95-104

18. Gabay C, Lamacchia C, Palmer G (2010) IL-1 pathways in inflammation and human diseases. Nat Rev Rheumatol 6(4):232-241

19. Gruber S, Hamedinger D, Bozsaky E et al (2015) Local hypoxia in oral mucosa (mouse) during daily fractionated irradiation - Effect of pentoxifylline. Radiother Oncol 116(3):404-408

20. Vissink A, Jansma J, Spijkervet FK et al (2003) Oral sequelae of head and neck radiotherapy. Crit Rev Oral Biol Med 14(3):199-212

21. Dorr W, Hendry JH (2001) Consequential late effects in normal tissues. Radiother Oncol 61(3):223-231
22. Murphy BA (2007) Clinical and economic consequences of mucositis induced by chemotherapy and/or radiation therapy. J Support Oncol 5(9 Suppl 4):13-21

23. Mizutani N, Fujikura Y, Wang YH et al (2002) Inflammatory and anti-inflammatory cytokines regulate the recovery from sublethal $\mathrm{X}$ irradiation in rat thymus. Radiat Res 157(3):281-289

24. Zhao W, Robbins ME (2009) Inflammation and chronic oxidative stress in radiation-induced late normal tissue injury: therapeutic implications. Curr Med Chem 16(2):130-143

25. Logan RM, Stringer AM, Bowen JM et al (2007) The role of pro-inflammatory cytokines in cancer treatment-induced alimentary tract mucositis: pathobiology, animal models and cytotoxic drugs. Cancer Treat Rev 33(5):448-460

26. Williams DA (2001) Inflammatory cytokines and mucosal injury. J Natl Cancer Inst Monogr 29:26-30

27. Vale ML, Benevides VM, Sachs D et al (2004) Antihyperalgesic effect of pentoxifylline on experimental inflammatory pain. $\mathrm{Br} \mathrm{J}$ Pharmacol 143(7):833-844

28. Liu J, Feng X, Yu M et al (2007) Pentoxifylline attenuates the development of hyperalgesia in a rat model of neuropathic pain. Neurosci Lett 412(3):268-272

29. Wordliczek J, Szczepanik AM, Banach M et al (2000) The effect of pentoxifiline on post-injury hyperalgesia in rats and postoperative pain in patients. Life Sci 66(12):1155-1164

30. Dorr W, Emmendorfer H, Weber-Frisch M (1996) Tissue kinetics in mouse tongue mucosa during daily fractionated radiotherapy. Cell Prolif 29(9):495-504

31. Groesdonk HV, Heringlake M, Heinze H (2009) Anti-inflammatory effects of pentoxifylline: importance in cardiac surgery. Anaesthesist 58(11):1136-1143

32. Ward A, Clissold SP (1987) Pentoxifylline. A review of its pharmacodynamic and pharmacokinetic properties, and its therapeutic efficacy. Drugs 34(1):50-97

33. Garcia FA, Reboucas JF, Balbino TQ et al (2015) Pentoxifylline reduces the inflammatory process in diabetic rats: relationship with decreases of pro-inflammatory cytokines and inducible nitric oxide synthase. J Inflamm (Lond) 12:33

34. Queiroz-Junior CM, Bessoni RL, Costa VV et al (2013) Preventive and therapeutic anti-TNF-alpha therapy with pentoxifylline decreases arthritis and the associated periodontal co-morbidity in mice. Life Sci 93(9-11):423-428

35. Bansal S, Wang W, Falk S et al (2009) Combination therapy with albumin and pentoxifylline protects against acute kidney injury during endotoxemic shock in mice. Ren Fail 31(9):848-854

36. Lima V, Brito GA, Cunha FQ et al (2005) Effects of the tumour necrosis factor-alpha inhibitors pentoxifylline and thalidomide in short-term experimental oral mucositis in hamsters. Eur J Oral Sci 113(3):210-217

37. Melo ML, Brito GA, Soares RC et al (2008) Role of cytokines (TNF-alpha, IL-1beta and KC) in the pathogenesis of CPT-11induced intestinal mucositis in mice: effect of pentoxifylline and thalidomide. Cancer Chemother Pharmacol 61(5):775-784

38. Li Q, Verma IM (2002) NF-kappaB regulation in the immune system. Nat Rev Immunol 2(10):725-734

39. Gaur U, Aggarwal BB (2003) Regulation of proliferation, survival and apoptosis by members of the TNF superfamily. Biochem Pharmacol 66(8):1403-1408

40. Takeuchi O, Akira S (2001) Toll-like receptors; their physiological role and signal transduction system. Int Immunopharmacol 1(4):625-635

41. Vasconcelos RM, Sanfilippo N, Paster BJ et al (2016) Host-microbiome cross-talk in oral mucositis. J Dent Res 95(7):725-733

42. Azzam EI, Jay-Gerin JP, Pain D (2012) Ionizing radiation-induced metabolic oxidative stress and prolonged cell injury. Cancer Lett 327(1-2):48-60 
43. Gloire G, Legrand-Poels S, Piette J (2006) NF-kappaB activation by reactive oxygen species: fifteen years later. Biochem Pharmacol 72(11):1493-1505

44. Haagen J, Krohn H, Rollig S et al (2009) Effect of selective inhibitors of inflammation on oral mucositis: preclinical studies. Radiother Oncol 92(3):472-476
45. Frings K, Gruber S, Kuess P et al (2016) Modulation of radiation-induced oral mucositis by thalidomide : Preclinical studies. Strahlenther Onkol 192(8):561-568 